\title{
Single- and Multiwalled Carbon Nanotubes with Phosphorus Based Flame Retardants for Textiles
}

\author{
D. Wesolek and W. Gieparda \\ Institute of Natural Fibres and Medicinal Plants, Ulica Wojska Polskiego 71b, 60-630 Poznan, Poland \\ Correspondence should be addressed to W. Gieparda; weronika.gieparda@iwnirz.pl
}

Received 7 March 2014; Revised 12 June 2014; Accepted 19 June 2014; Published 8 July 2014

Academic Editor: Zheng-Hong Huang

Copyright (C) 2014 D. Wesolek and W. Gieparda. This is an open access article distributed under the Creative Commons Attribution License, which permits unrestricted use, distribution, and reproduction in any medium, provided the original work is properly cited.

\begin{abstract}
Due to growing popularity of composites, modification methods to obtain the best properties are searched for. The aim of the study is to reduce the flammability of textile materials using nanocomposite polymer back-coating. Different types of carbon nanotubes (single- and multiwalled) and different phosphorus flame retardants (ammonium polyphosphates and melamine polyphosphate) were introduced into the resin and then the fabrics were covered by the obtained composites. Homogeneous dispersion of multiwalled carbon nanotubes in the polyurethane resin was obtained by sonification, which was confirmed by scanning electron microscopy. Flammability tests of fabrics coated by modified polyurethane resin were carried out using pyrolysis combustion flow calorimeter (PCFC) and thermal stability of textiles was evaluated. Also, organoleptic estimation of coatings was conducted (flexibility and fragility). The use of polymer nanocomposites with phophorus flame retardants as a back-coating for textiles effectively reduces flammability and improves thermal stability of the fabric. Furthermore, the synergistic effect beetwen carbon nanotubes and phosphorous compound occurs. The resulting coatings are flexible and do not crack or change the feel of fabrics.
\end{abstract}

\section{Introduction}

Rapid development of the economy increases demand for new engineering materials. Traditional materials and textiles are increasingly often being replaced by modern composites and modified textiles showing improved useful properties. Improvement of existing and creation of new material properties are the most important reasons for functionalization of textiles. Many studies have investigated thermal stability and flammability of materials with addition of different types of flame retardants $[1,2]$. Enhancement of thermal stability and fire resistance based on the use of polymer composites filled with various types of nanoadditives has been extensively developed in the recent years [2-4]. Many other materials besides polymer composites must fulfill requirements for flammability. More and more studies are being conducted to reduce the flammability of textiles $[5,6]$, as these materials are used in furniture, interior finishing, and the transport industry (seat fabrics) and in the production of clothing. Polymer nanocomposites offer possibility of developing a new class of back-coating for textiles.
Carbon nanotubes (CNT) are allotropes of carbon with a cylindrical nanostructure. The CNT walls resemble rolledup graphite-like sheets with strong covalent $\mathrm{sp}^{2}$ bonds. These cylindrical carbon molecules have unusual properties, which are valuable for nanotechnology, electronics, optics, and other fields of materials science and technology [7].

There are a number of studies investigating these materials as a flame suppressing additive. Researchers such as Beyer $[8,9]$ Rahatekar et al. [10], Hapuarachchi and Peijs [11], Kashiwagi et al. [12-14], Schartel et al. [15, 16], and Bourbigot et al. [17] have been investigating flammability of various sets of polymeric composites together with multiwalled nanotubes composition.

Our previous studies on flammability of epoxy and polyurethane composites with nanoparticles brought interesting results of the flammability properties of nanocomposites $[18$, 19]. Also our studies on flammability of epoxy/CNTs composites with different fillers [20] such as expandable graphite, montmorillonite, or intumescent compositions showed that the addition of those fillers to epoxy/CNT composites had 
a considerable effect on reduction of heat release rate and also on delaying time to ignition. Our latest studies on reduction of flammability in polyurethane resins with montmorillonite and carbon nanotubes as fillers [21] indicated that the use of the nanoscale particles in a polymer matrix can give satisfactory results in flammability tests.

The aim of this work is reducing flammability of textiles by using a polymer nanocomposite back-coating with addition of conventional phosphorus flame retardants. Different types of carbon nanotubes (single-walled-SWCNT, multiwalled-MWCNT) were added to polyurethane (PU) resin. When the dispersion of nanotubes was homogenous, then different flame retardants (melamine polyphosphate-MPP, ammonium polyphosphates APP423 and APP750) were added. After that the fabrics were coated by those composites.

\section{Materials and Methods}

2.1. Materials. The following materials were used:

(i) polyurethane resin Edolan UH (PU) supplied by Tanatex Chemicals;

(ii) two types of carbon nanotubes-single-walled carbon nanotubes (SWCNT) and multiwalled carbon nanotubes (MWCNT) supplied by a Belgian company Nanocyl S.A.;

(iii) two types of ammonium polyphosphate: APP423 and APP750 - supplied by Clariant;

(iv) melamine polyphosphate (MPP) supplied by a Polish company Ciech;

(v) fabrics made of natural fibers (f) $-45 \%$ cotton $/ 55 \%$ flax, surface mass $310 \mathrm{~g} / \mathrm{m}^{2}$.

2.2. Methods. The dispersion of nanofillers was studied by scanning electron microscopy (SEM) on the Hitachi S-3400 $\mathrm{N}$ microscope.

Thermogravimetric analysis was carried out with a thermal analyser Setaram Setsys 1200 at $10^{\circ} \mathrm{C} / \mathrm{min}$ under air atmosphere. The weight of the samples was close to $30 \mathrm{mg}$. The temperatures of the $5 \%$ weight loss were determined.

The effect of the polymer nanocomposite back-coating on the flammability of natural fibre fabric was analyzed by a pyrolysis combustion flow calorimeter (PCFC). The heating rate was $1^{\circ} \mathrm{C} / \mathrm{s}$. Pyrolysis temperature ranged between 75 and $750^{\circ} \mathrm{C}$, and the combustion temperature was $900^{\circ} \mathrm{C}$. The flow was a mixture of $\mathrm{O}_{2} / \mathrm{N}_{2} 20 / 80 \mathrm{~cm}^{3} / \mathrm{min}$ and the sample weight at $5( \pm 0,01) \mathrm{mg}$. The specific heat release rate $(\mathrm{HRR})$ and maximum specific heat release rate $\left(\mathrm{HRR}_{\max }\right)$ were determined.

2.3. Sample Preparation. The composites were prepared from polyurethane resin, single-walled nanotubes as well as multiwalled carbon nanotubes. The mixtures were homogenized for 2 hours by the ultrasonic processor. Conventional compounds reducing flammability were used in addition to CNT, including ammonium polyphosphates (APP 423 and APP 750) and melamine polyphosphate (MPP). The abovementioned flame retardants were added with using a high speed homogenizer (20000 RPM). Such modified resins were applied on one side of the fabric surface in the form of a coating of the fabric surface using Mathis Labcoater. The coatings were dried at $80^{\circ} \mathrm{C}$ and then crosslinked at $140^{\circ} \mathrm{C}$.

\section{Results and Discussion}

3.1. Dispersion of Carbon Nanotubes. The flammability of PU/CNT composites depends strongly on the homogeneous distribution of carbon nanotubes into the polymer matrix. The ultrasonification process used in the preparation of the composites ensures the proper distribution of multiwalled carbon nanotubes in the entire volume of the sample and prevents the formation of agglomerates (Figure 1(a)). However, in the case of SWNT, on the SEM pictures is visible that dispersion is slightly worse. Besides individual nanotubes, agglomerates can be observed in a few places (Figure 1(b)).

3.2. Microcalorimetric Analysis. Flammability studies with the pyrolysis combustion flow calorimeter showed that combustion of the fabrics coated by the composites with carbon nanotubes only is much less intensive in comparison with the pure fabric. After the addition of phosphorus compounds the combustion is further reduced. (Figures 2(a) and 2(b)) significant differences were not observed in the maximum heat release rate between fabrics coated by singleor multiwalled carbon nanotubes. Numerous reports in the literature demonstrated the superiority of SWCNT because of their better physical properties [22-25]. However, Kashiwagi et al. showed in their report the importance of obtaining adequate dispersion of this type of carbon nanotubes, in order to obtain a significant improvement of the flammability [12]. The result achieved in this study (a small difference in reducing the flammability of fabric coated by polymer nanocomposites with SWCNT and MWCNT) might also be related with insufficient dispersion, due to the fact that singlewalled nanotubes were harder to undergo uniform dispersion in a polymer matrix. $\mathrm{HRR}_{\max }$ reduction for fabrics coated only by polyurethane/nanotubes was similar (regardless of the type of nanotubes-SWCNT or MWCNT) and reached approximately $20 \%$. The addition of MPP to the composition caused large reduction of $\mathrm{HRR}_{\max }$ - from $200 \mathrm{~W} / \mathrm{g}$ (pure fabric) to approximately $120 \mathrm{~W} / \mathrm{g}$. The addition of ammonium polyphosphates, in turn, reduced further this parameter, to approximately $90 \mathrm{~W} / \mathrm{g}$. Changes in the $\mathrm{HRR}_{\max }$ for the addition of $5 \%$ of flame retardants proceeded in a way comparable to that for $15 \%$ addition. So the $5 \%$ weight fraction of flame retardants seemed to be the optimal amount to reduce combustion of fabrics. The addition of APP 423 to coating with multiwalled carbon nanotubes is an exception with a significant reduction of heat release rate from $99(5 \%)$ to $67 \mathrm{~W} / g(15 \%)$. Polyurethane with ammonium polyphosphate 423 was the best coating in the amount of $15 \%$ and multiwalled carbon nanotubes. The coating reduced the maximum heat release rate by $66 \%$ as compared to the neat fabric.

The curves of heat release rate (HRR) for selected samples are presented in Figure 3. The curve shapes are visibly 


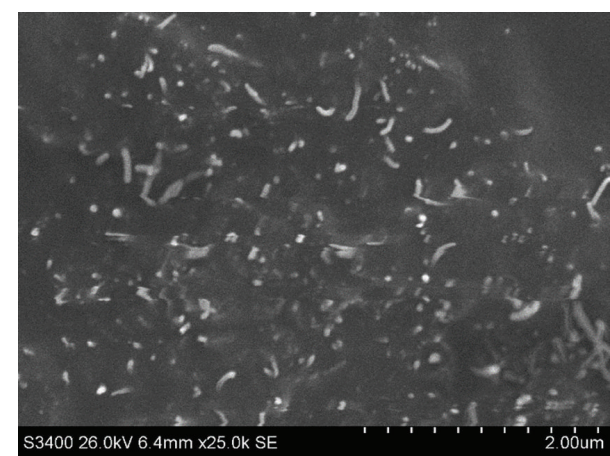

(a)

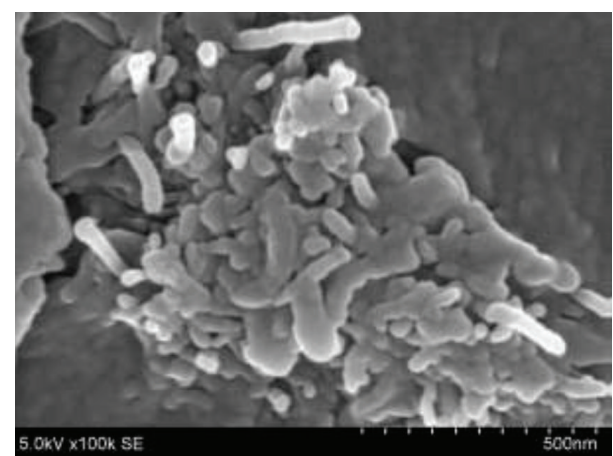

(b)

FIGURE 1: (a) SEM image of PU/MWCNT composite. (b) SEM image of PU/SWCNT composite.

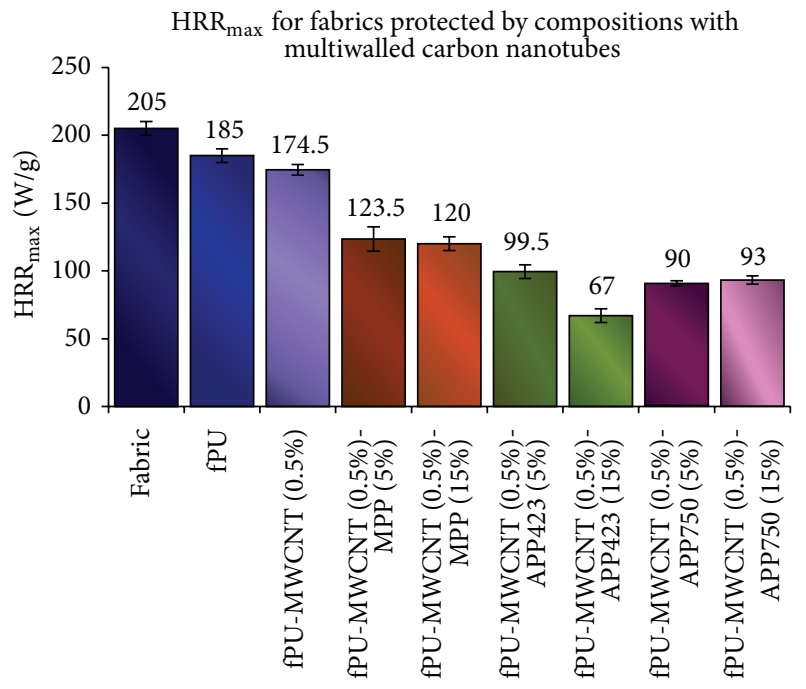

(a)

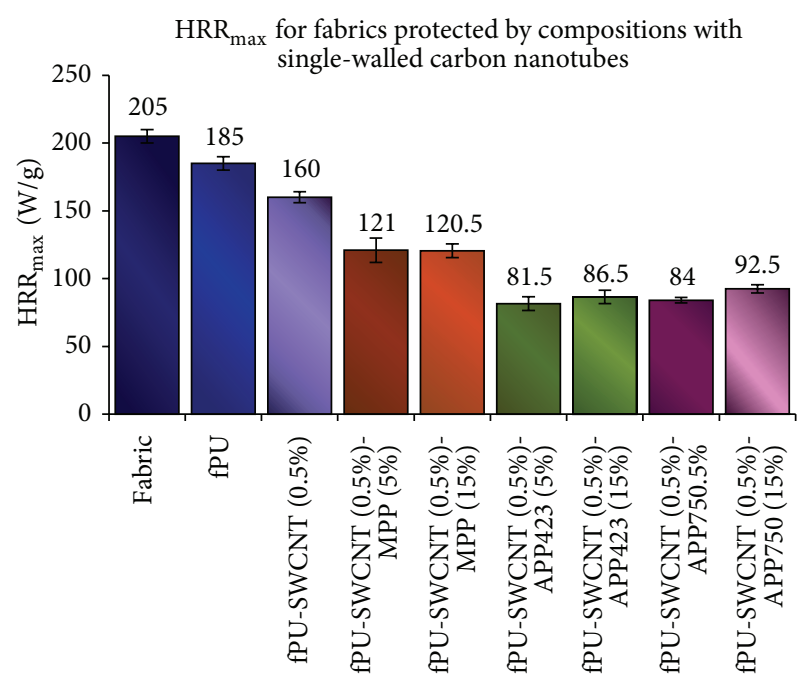

(b)

FIGURE 2: (a) $\mathrm{HRR}_{\max }$ for fabrics protected by compositions with multiwalled carbon nanotubes. (b) $\mathrm{HRR}_{\max }$ for fabrics protected by compositions with single-walled carbon nanotubes.

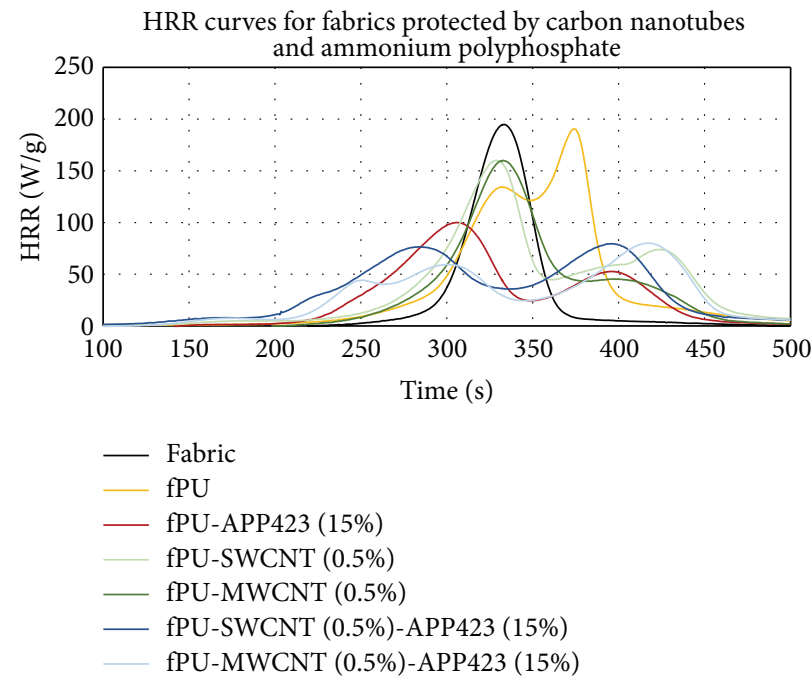

FIGURE 3: HRR curves for selected fabrics protected by nanofillers and phosphorous compounds. 
different for the fabrics with polyurethane coating in comparison to the pure fabric. The coating by neat polyurethane resulted in forming of two HRR peaks, the first one was reduced with respect to the pure fabric by $30 \%$ and the second peak was similar to the pure fabric peak, but it occurred 60 seconds later. Introducing of the carbon nanotubes into the polyurethane, in turn, caused significant reduction in the second peak of heat release rate (from $200 \mathrm{~W} / \mathrm{g}$ for fPU to $50-70 \mathrm{~W} / \mathrm{g}$ for $\mathrm{fPU}-\mathrm{CNT}$ depending on the type of carbon nanotubes), and further delayed this peak. The first peak increased in comparison to fPU but decreased in comparison to pure fabric. The addition of ammonium polyphopsphate to polyurethane coating (without CNT) led to the reduction in the first peak by half in comparison to pure fabric. Synergistic effect between nanofiller and ammonium polyphosphates is visible when comparing HRR curves for fabric coated by PU/APP423 and PU/CNT with the curve for the fabric coated by PU/APP423/CNT. The addition of carbon nanotubes and APP 423 together into the polymer matrix reduced both peaks of heat release rate from $200 \mathrm{~W} / \mathrm{g}$ (pure fabric) to $50 \mathrm{~W} / \mathrm{g}$ (first peak) and $70 \mathrm{~W} / \mathrm{g}$ (second peak) and it constituted the largest reduction in those peaks of all the samples.

During combustion, phosphorous flame retardants dilute the amount of gaseous combustibles by releasing water in the gas phase. Furthermore, APP is assumed to be an intumescent flame retardant which forms an expanded and foamed char layer. Thus, it can act a physical barrier to mass and heat transfer between the polymer and the superficial zone where the combustion of the polymer occurs. Presence of CNTs in this char layer might have strengthened the char and led to a synergistic effect. Observations of the residue recovered after combustion were performed by numerous researchers [26, 27] and this hypothesis has been confirmed. The char formed during combustion is much less cracked in the composites with APP and MWCNT.

Time to ignition for the protected fabrics showed reduction with respect to neat polymer. This behaviour is in agreement with the previously reported data $[12,28]$.

3.3. Thermogravimetric Analysis. Thermal stability of composites was analyzed by thermogravimetric analysis (TGA). In Figure 4 thermogravimetric curves in the range of 90$100 \%$ weight loss, for samples with different phosphorous compounds, are shown. The temperature of $5 \%$ weight loss was determined in order to compare the initial step of sample decomposition. Thermal decomposition of unprotected fabric began at $T_{d}=297^{\circ} \mathrm{C}$ (5\% weight loss) and decomposition of fabric covered with polyurethane at $319^{\circ} \mathrm{C}$. A slight increase of the temperature to $323^{\circ} \mathrm{C}$ was observed for the fabric with the coating containing carbon nanotubes. In other cases, with the addition of phosphorous compounds, the decomposition of coated fabrics began at lower temperatures.

In Figure 5 selected thermogravimetric curves are shown (unprotected fabric, fabric protected by PU, PU/MWCNT, and PU/MWCNT/APP15\% - the best composition). In natural fibres, the degradation involves two main steps (see the thermogravimetric curve for pure fabric). The first one is the thermal depolymerisation of the hemicellulose and the cleavage of glycosidic linkages of cellulose $\left(340-360^{\circ} \mathrm{C}\right)$ and the second one is related to the decomposition of the $\alpha$ cellulose $\left(370-580^{\circ} \mathrm{C}\right)[29,30]$. The decomposition of lignin takes place in a broad range of temperature between 200 and 500 [31]. These two steps were also visible for fabrics coated by composites with polyurethane and carbon nanotubes. However, the second step begins at higher temperatures. Three steps of the degradation were visible for the fabrics coated by composites with carbon nanotubes and phosphorous additive. The first step started earlier and shifted to lower temperatures, while the second one was characterized by a very slow weight loss due to flame retardant action of polyphosphate. The third step was also milder and slower.

Flame retardants have two opposing functions in the thermal stability of the polymer nanocomposite, one is the catalytic effect towards the degradation of the polymer matrix which would accelerate thermal decomposition, and the other is its barrier effect and formation of char, which should improve the thermal stability by lowering the intensity of the combustion process. This is clearly visible in our studies. Thermal decomposition of fabrics protected by the polymer nanocomposite starts earlier but the combustion is slower and less intense.

Phosphorous compounds are intumescent flame retardants which improve thermal stability by changing pyrolytic path of the polymeric materials [32]. Under oxidative conditions, at temperatures above $260^{\circ} \mathrm{C}$, APP starts to degrade producing phosphoric acid, which then is converted to polyphosphoric acid, which enhances cross-linking of polymer fragments to form a carbonaceous char protecting the underlying polymer from degradation [33]. When CNTs were incorporated to the mixture of PU/APP423 the intensity of degradation was significantly lowered. That synergistic effect was more pronounced at temperatures above $350^{\circ} \mathrm{C}$. This can be attributed to efficient barrier effect of carbonaceous char formed by the incorporation of CNTs and APP fillers. The combination of CNTs and APP fillers leads to formation of stronger and more cohesive char, which can reduce the diffusion of volatile compounds [26].

3.4. The Appearance of Fabrics. It is important that the fabric after coating remained soft and flexible and the protecting coat itself was stable and did not crack. In order to evaluate the prepared samples in this respect, the organoleptic analysis of the coatings and fabrics was made. It was found that fabrics after treatment did not change in terms of flexibility, softness, and feel. The coatings did not crack.

\section{Summary}

The protection obtained in the form of coatings for natural fabrics improves the flammability properties. The addition of $0,5 \%$ of carbon nanotubes to the polyurethane resin coating decreases the value of maximum heat release rate by $20 \%$. Enriching the composite coating additionally with phosphorous flame retardants used in the study results in a further reduction of $\mathrm{HRR}_{\max }$. Single-walled carbon nanotubes show 
Thermogravimetric analysis of fabrics

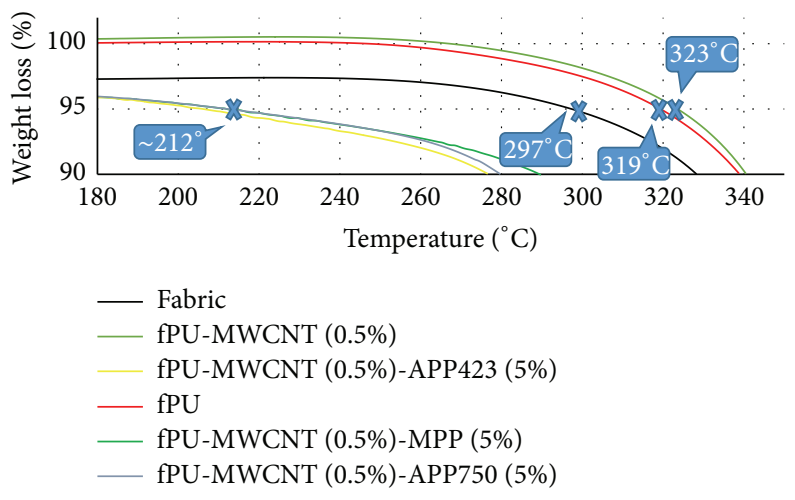

Figure 4: Thermogravimetric curves in the range of $90-100 \%$ weight loss for the protected fabrics with coatings containing different phosphorous compounds.

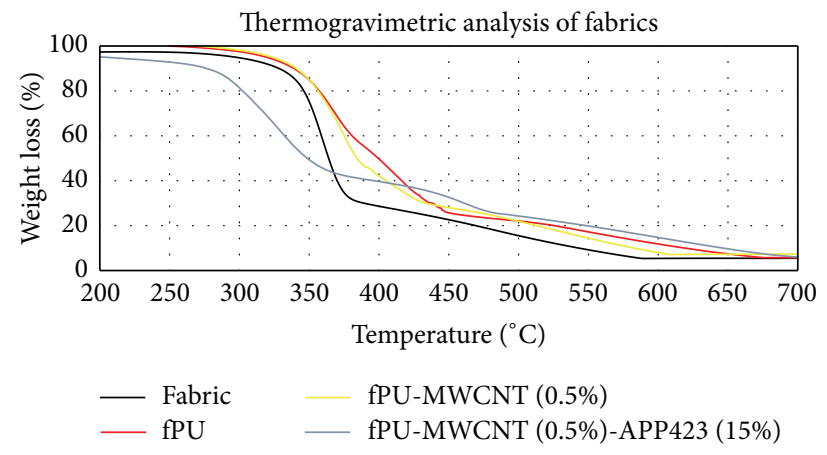

FIgURE 5: Thermogravimetric curves for the selected fabrics.

similar properties in terms of reduction of heat release rate to those of multiwalled carbon nanotubes. The thermal degradation of fabrics coated by polymer nanocomposites (without phosphorous compounds) starts at higher temperatures than in case of pure fabric. After addition of phosphorous flame retardants the temperatures of the $5 \%$ weight loss are reduced but the decomposition is much slower and milder.

The most advantageous composition in reducing fabrics flammability and in terms of the appearance of coating (flexibility and elasticity) is the composition containing polyurethane resin with ammonium polyphopsphate 423 in the amount of $15 \%$ and $0,5 \%$ of multiwalled carbon nanotubes.

\section{Conflict of Interests}

The authors declare that there is no conflict of interests regarding the publication of this paper.

\section{Acknowledgments}

The study has been carried out within the Key ProjectPOIG.01.03.01-00-004/08 Functional nano- and microtextile materials-NANOMITEX cofinanced by the European Union with the financial resources of the European Regional Development Fund and the National Centre for Research and Development within the framework of the Innovative Economy Operational Programme, 2007-2013, Priority 1. Research and development of modern technologies, Activity 1.3. Supporting R\&D projects for enterprises undertaken by scientific organizations, Subactivity 1.3.1. Development projects.

\section{References}

[1] R. Jeencham, N. Suppakarn, and K. Jarukumjorn, "Effect of flame retardants on flame retardant, mechanical, and thermal properties of sisal fiber/polypropylene composites," Composites Part B: Engineering, vol. 56, pp. 249-253, 2014.

[2] P. Rybiński and G. Janowska, "Influence synergetic effect of halloysite nanotubes and halogen-free flame-retardants on properties nitrile rubber composites," Thermochimica Acta, vol. 557, pp. 24-30, 2013.

[3] Z. Wu, H. Wang, X. Tian et al., "Mechanical and flame-retardant properties of styrene-ethylene-butylene-styrene/carbon nanotube composites containing bisphenol A bis(diphenyl phosphate)," Composites Science and Technology, vol. 82, pp. 8-14, 2013.

[4] G. Huang, S. Wang, P. Song, C. Wu, S. Chen, and X. Wang, "Combination effect of carbon nanotubes with graphene on intumescent flame-retardant polypropylene nanocomposites," Composites A: Applied Science and Manufacturing, vol. 59, pp. 18-25, 2014. 
[5] A. R. Horrocks, "Flame retardant challenges for textiles and fibres: new chemistry versus innovatory solutions," Polymer Degradation and Stability, vol. 96, no. 3, pp. 377-392, 2011.

[6] A. R. Horrocks, “Textile flammability research since 1980personal challenges and partial solutions," Polymer Degradation and Stability, vol. 98, no. 12, pp. 2813-2824, 2013.

[7] R. Malik, N. Alvarez, M. Haase et al., "Chapter 13-carbon nanotube sheet: processing, characterization and applications," in Nanotube Superfiber Materials, chapter 13, pp. 349-387, 2014.

[8] G. Beyer, "Short communication: carbon nanotubes as flame retardants for polymers," Fire and Materials, vol. 26, no. 6, pp. 291-293, 2002.

[9] G. Beyer, "Carbon nanotubes-a new class of flame retardants for polymers," Gummi, Fasern, Kunststoffe, vol. 55, no. 9, pp. 596-549, 2002.

[10] S. S. Rahatekar, M. Zammarano, S. Matko et al., "Effect of carbon nanotubes and montmorillonite on the flammability of epoxy nanocomposites," Polymer Degradation and Stability, vol. 95, no. 5, pp. 870-879, 2010.

[11] T. D. Hapuarachchi and T. Peijs, "Multiwalled carbon nanotubes and sepiolite nanoclays as flame retardants for polylactide and its natural fibre reinforced composites," Composites A: Applied Science and Manufacturing, vol. 41, no. 8, pp. 954-963, 2010.

[12] T. Kashiwagi, F. Du, K. I. Winey et al., "Flammability properties of polymer nanocomposites with single-walled carbon nanotubes: effects of nanotube dispersion and concentration," Polymer, vol. 46, no. 2, pp. 471-481, 2005.

[13] T. Kashiwagi, E. Grulke, J. Hilding, R. Harris, W. Awad, and J. Douglas, "Thermal degradation and flammability properties of poly(propylene)/carbon nanotube composites," Macromolecular Rapid Communications, vol. 23, no. 13, pp. 761-765, 2002.

[14] T. Kashiwagi, E. Grulke, J. Hilding et al., "Thermal and flammability properties of polypropylene/carbon nanotube nanocomposites," Polymer, vol. 45, no. 12, pp. 4227-4239, 2004.

[15] B. Schartel, P. Pötschke, U. Knoll, and M. Abdel-Goad, "Fire behaviour of polyamide 6/multiwall carbon nanotube nanocomposites," European Polymer Journal, vol. 41, no. 5, pp. 1061-1070, 2005.

[16] B. Schartel, U. Braun, U. Knoll et al., "Mechanical, thermal, and fire behavior of bisphenol a polycarbonate/multiwall carbon nanotube nanocomposites," Polymer Engineering and Science, vol. 48, no. 1, pp. 149-158, 2008.

[17] S. Bourbigot, S. Duquesne, and C. Jama, "Polymer nanocomposites: how to reach low flammability?" Macromolecular Symposia, vol. 233, pp. 180-190, 2006.

[18] M. Wladyka-Przybylak, D. Wesolek, W. Gieparda, A. Boczkowska, and E. Ciecierska, "Functionalization effect on physico-mechanical properties of multi-walled carbon nanotubes/epoxy composites," Polymers for Advanced Technologies, vol. 22, no. 1, pp. 48-59, 2011.

[19] W. Gieparda, D. Wesołek, and S. Rojewski, "Montmorillonite and carbon nanotubes filled polyurethane back-coating for textiles with improved flammability properties and thermal stability," Journal of Nanostructured Polymers and Nanocomposites, vol. 8, no. 3, pp. 82-88, 2012.

[20] M. Wladyka-Przybylak, D. Wesolek, W. Gieparda, and M. Przybylak, "Flame retardant effects of magnesium hydroxide and intumescent additives for epoxy/carbon nanotube composites," in Proceedings of the 1st International Symposium on Flame Retardant Materials Technologies, p. 174, Chengdu, China, 2010.
[21] S. Rojewski, R. Gąsiorowski, W. Gieparda, D. Wesołek, and M. Władyka-Przybylak, "Montmorillonite and carbon nanotubes as a reducing flammability fillers for polymers resins," in Proceedings of the 4th ECNP Young Researcher Conference, Paris, France, 2011.

[22] R. Haggenmueller, H. H. Gommans, A. G. Rinzler, J. E. Fischer, and K. I. Winey, "Aligned single-wall carbon nanotubes in composites by melt processing methods," Chemical Physics Letters, vol. 330, no. 3-4, pp. 219-225, 2000.

[23] P. M. Ajayan, L. S. Schadler, C. Giannaris, and A. Rubio, "Singlewalled carbon nanotube-polymer composites," Strength and Weakness Advanced Materials, vol. 12, pp. 750-753, 2000.

[24] A. A. Mamedov, N. A. Kotov, M. Prato, D. M. Guldi, J. P. Wicksted, and A. Hirsch, "Molecular design of strong singlewall carbon nanotube/polyelectrolyte multilayer composites," Nature Materials, vol. 1, no. 3, pp. 190-194, 2002.

[25] F. Du, J. E. Fischer, and K. I. Winey, "Coagulation method for preparing single-walled carbon nanotube/poly(methyl methacrylate) composites and their modulus, electrical conductivity, and thermal stability," Journal of Polymer Science B: Polymer Physics, vol. 41, no. 24, pp. 3333-3338, 2003.

[26] S. Bourbigot, S. Duquesne, G. Fontaine, S. Bellayer, T. Turf, and F. Samyn, "Polymer nanocomposites with and without convencional flame retardants: Reaction to fire and synergy," Molecular Crystals and Liquid Crystals, vol. 486, pp. 325-339, 2008.

[27] M. C. Costache, M. J. Heidecker, E. Manias et al., "The influence of carbon nanotubes, organically modified montmorillonites and layered double hydroxides on the thermal degradation and fire retardancy of polyethylene, ethylene-vinyl acetate copolymer and polystyrene," Polymer, vol. 48 , no. 22 , pp. 6532 6545, 2007.

[28] M. Delichatsios, in Proceedings of the 4th International Conference on Polymer Modification, Degradation and Stabilization (MoDeSt '06), F. La Mantia, Ed., Modest Society, Palermo, Italy, 2006.

[29] K. C. Manikandan Nair, S. Thomas, and G. Groeninckx, "Thermal and dynamic mechanical analysis of polystyrene composites reinforced with short sisal fibres," Composites Science and Technology, vol. 61, no. 16, pp. 2519-2529, 2001.

[30] C. Albano, J. González, M. Ichazo, and D. Kaiser, "Thermal stability of blends of polyolefins and sisal fiber," Polymer Degradation and Stability, vol. 66, no. 2, pp. 179-190, 1999.

[31] N. E. Marcovich, M. M. Reboredo, and M. I. Aranguren, "Modified woodflour as thermoset fillers ii. Thermal degradation of woodflours and composites," Thermochimica Acta, vol. 372, no. $1-2$, pp. 45-57, 2001.

[32] B. Schartel, A. Weiß, H. Sturm et al., "Layered silicate epoxy nanocomposites: formation of the inorganic-carbonaceous fire protection layer," Polymers for Advanced Technologies, vol. 22, no. 12, pp. 1581-1592, 2011.

[33] E. Kandare, B. K. Kandola, D. Price, S. Nazaré, and R. A. Horrocks, "Study of the thermal decomposition of flameretarded unsaturated polyester resins by thermogravimetric analysis and Py-GC/MS," Polymer Degradation and Stability, vol. 93, no. 11, pp. 1996-2006, 2008. 

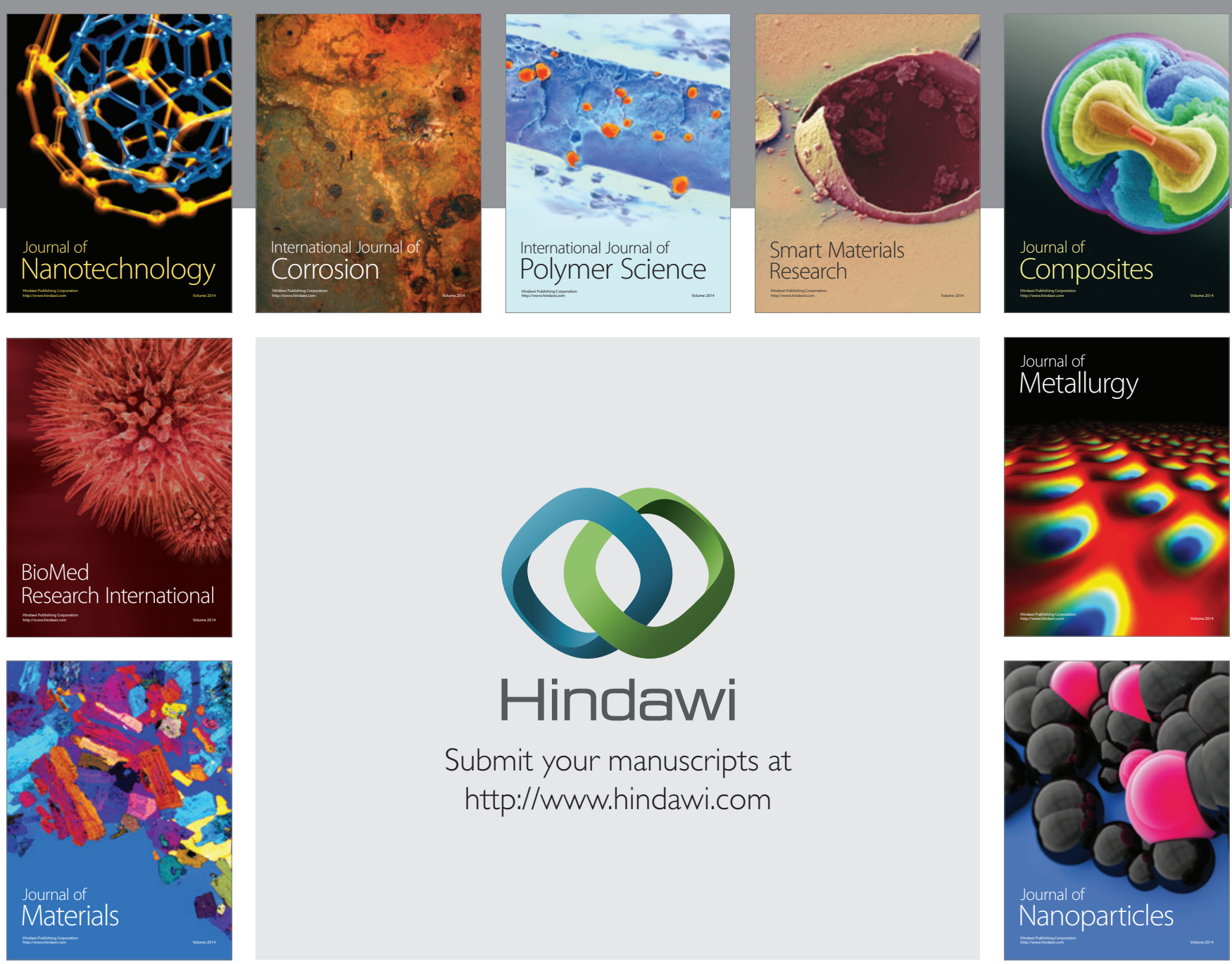

Submit your manuscripts at http://www.hindawi.com
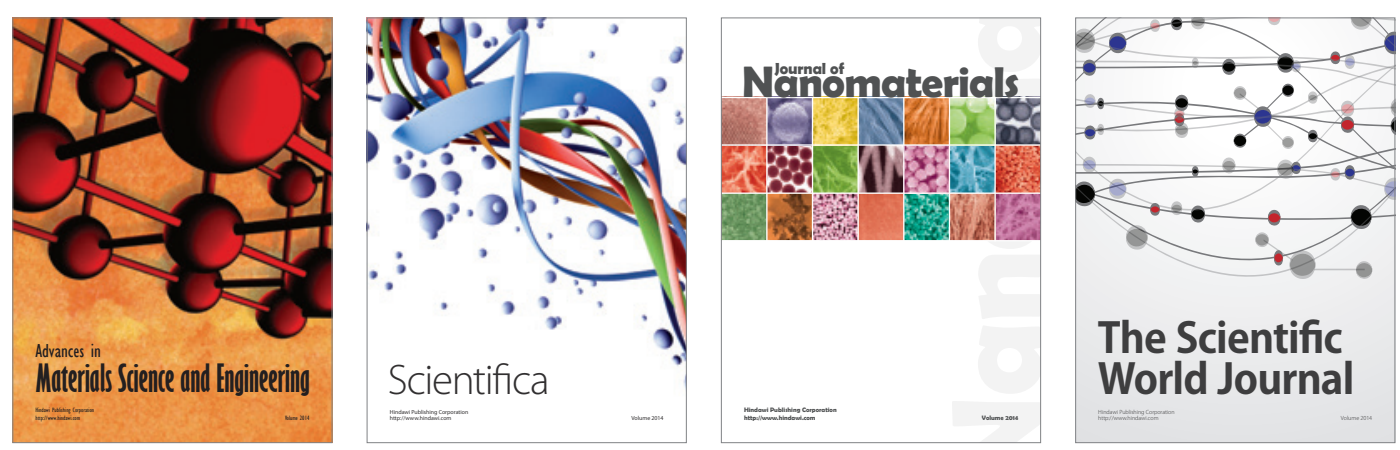

\section{The Scientific World Journal}
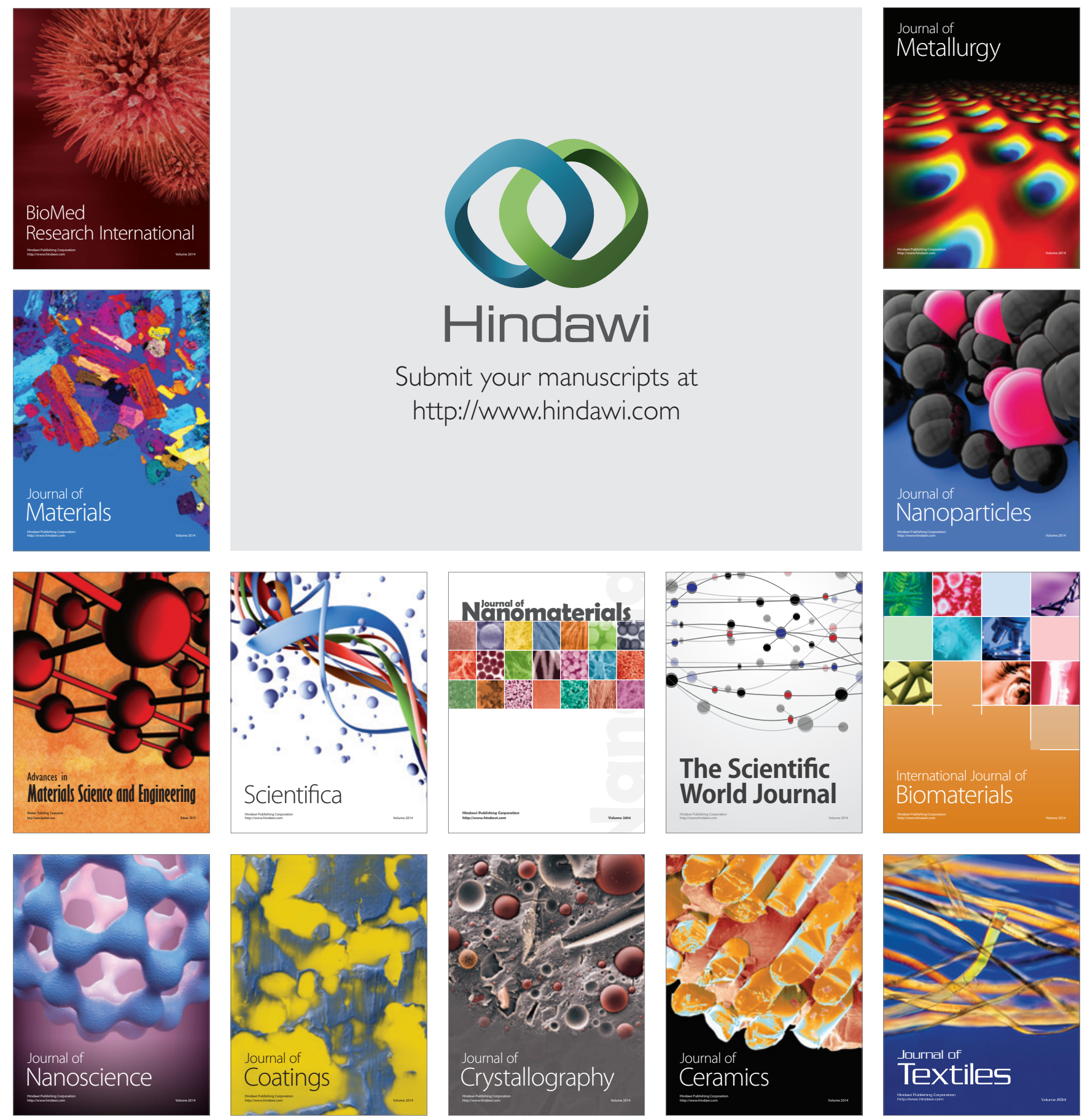